\title{
Development and prevention of preputial sucking in veal calves
}

J. G. de Wilt (Institute of Agricultural Engineering (IMAG), P.O.Box 43, 6700 AA Wageningen, Netherlands) ${ }^{*}$

Received 9 September 1986; accepted 31 October 1986

\begin{abstract}
The development of the sucking behaviour of bucket-fed veal calves in groups of five was described from the age of two to eight weeks. The influence of extra water supply and early feeding method on the occurrence of preputial sucking was investigated.

Key words: veal calves, intersucking, urine intake, fluid intake, feeding method, sensitive period.
\end{abstract}

Introduction. The group housing of bucket fed veal calves may be a practical alternative to the traditional housing in individual crates. However, a major problem with housing predominantly male calves in groups is the mutual sucking of the prepuce, accompanied by the intake of urine which reduces milk consumption and growth rate. This study seeks means of preventing preputial sucking in group housing.

\section{Development of sucking behaviour}

Materials and methods. In a pilot experiment, ten one-week old male calves (Dutch Friesian (DF) $\times$ Holstein Friesian (HF), with unknown sucking history), were housed in two groups of five on concrete slatted floors with straw bedding. They were fed a commercial milk replacer from open buckets twice daily. Video observations were made over 24-hour periods during seven weeks.

Results and discussion. Nine out of ten calves showed an initial preference for sucking a particular physical object or body part other than the prepuce. These preferences differed among individuals and usually changed over time. During the second and third week eight out of ten calves developed a preference toward sucking the prepuce of penmates. Preputial sucking occupied several hours dispersed over the day, whereas other sucking occurred primarily for 10-30 minutes after each feading. The preference for preputial sucking in individual calves was continued until the duration of sucking drecreased to less than half an hour per day in weeks 6-8 of the experiment. Two of the ten calves were never observed to suck the prepuce. Preputial sucking seems a highly preferred sucking activity, but the finding of the prepuce may not be accomplished by all calves. An initial variety of changing prefe-

\footnotetext{
${ }^{*}$ Present address: Directorate for Agricultural Research (DLO), P.O.Box 59, 6700 AB Wageningen. Netherlands.
} 
rences followed by an established preference also occurs when a newborn calf searches for the udder. The two hypotheses treated below were derived from this analogy.

\section{Effect of water supply on preputial sucking}

Introduction. The release of fluids is probably an important reinforcing factor in both preputial and udder searching (J. H. M. Metz, unpublished results). Perhaps the provision of only small amounts of fluid during the first weeks of the fattening period (3-4 l per calf per day) is one of the causes of preputial sucking. If so, the supply of extra water should reduce the incidence of preputial sucking.

Materials and methods. In three replicate experiments, 3-5 1 water $\left(25-35^{\circ} \mathrm{C}\right)$ was provided per individual calf two or three times per day in open buckets to a total of 60 calves in groups of five on wooden slatted floors, whereas 60 other similarly housed calves did not receive extra water. All calves were male $\mathrm{DF} \times \mathrm{HF}$ and one week old at the start of the experiment.

Results and discussion. Total fluid intake (milk replacer + water) was on average two to three times higher in the extra water groups than in the control groups of calves (for instance, in week 3, $14 \mathrm{l}$ against $5 \mathrm{l}$ per calf per day). Nevertheless, in extra water groups 10 calves started preputial sucking against 14 calves in the group without extra water; there was no significant influence of an extra supply of water on the incidence of preputial sucking. Therefore, deficit of fluid as such seems no major factor in preputial sucking.

\section{Effect of early feeding method on preputial sucking}

Introduction. Since the ability to find the udder is dependent on sucking experience during the first week of life (Finger \& Brummer, 1969), contacting and sucking the prepuce may also be related to early sucking experience.

Materials and methods. To test this hypothesis, a total of 97 male DF $\times$ HF calves were observed in three separate experiments to determine the effect of first-week sucking experience on preputial sucking tendencies when subsequently housed in groups. Calves which initially had been fed with open buckets $(n=50)$, teat buckets $(n=32)$, and the mothyer cow $(n=15)$ were housed in groups of five on wooden slats or concrete slats covered with straw. All were fed milk replacer from open buckets twice daily. In two experiments, artificial teats were available.

Results and discussion. None of the total of 32 teat bucket reared calves engaged in preputial sucking, compared to 24 out of 50 open bucket reared calves and 5 out of 15 cow reared calves. This suggests that early teat bucket feeding reduces the incidence of preputial sucking compared to rearing with an open bucket or the udder. Experience with sucking at a particular object during a sensitive period just after birth may induce a relative indifference to sucking novel objects. The difference between cues related to artificial teat sucking and preputial sucking may inhibit preputial sucking in teat bucket reared calves. Likewise, the similarity between stimuli associated with the udder and prepuce location may facilitate contacting the prepuce and promote preputial sucking in cow reared calves. Among open bucket reared calves, which lack adequate sucking experience, the reponsiveness to novel 
objects may be prolonged (Bateson, 1983) and these calves may therefore still contact and suck the prepuce of penmates.

Conclusions. Preputial sucking is a highly preferred sucking activity among male veal calves in group pens, which is probably stimulated by the release of urine, but finding the prepuce may not be accomplished by all calves. The provison of extra water does not diminish the occurrence of preputial sucking, but teat bucket feeding just after birth may reduce the incidence of preputial sucking compared to rearing from an open bucket or the udder.

\section{References}

Bateson, P., 1983. Genes, environment and the development of behaviour. In: F. R. Halliday \& P. J. B. Slater (Eds.), Animal behaviour, Vol. 3, p. 52-81. Blackwell Scientific Publications, Oxford.

Finger, K. H. \& H. Brummer, 1969. Beobachtungen über das Saugverhalten mutterlos aufgezogener Kälber. Deutsche Tierärztliche Wochenschrift 76: 665-667.

This synopsis is based on part of a doctoral thesis entitled 'Behaviour and welfare of veal calves in relation to husbandry systems', Agrycultural University, 1985, 138 pp, 45 figs, 54 tables, 4 photos, 195 refs, 8 appendices. English; Dutch summary.

Available as paper copy (order R055P, price 30 including postage) or microfiche (order R055M, price f 17.50 including postage) at: NARD, clo Pudoc, P.O.Box 4, 6700 AA Wageningen, Netherlands (telex 45015 blhwg). 